\title{
DOCTRINA \\ Big data: Nuevos desafíos en materia de libre competencia
}

\author{
Big data: New challenges for competition law
}

\author{
María Francisca Labbé Figueroa \\ Universidad del Desarrollo, Chile
}

\begin{abstract}
RESUMEN En este artículo explicamos cómo el big data presenta nuevos desafíos más allá de la protección de la privacidad. En específico, comentamos cómo puede afectar la competencia en los mercados, al facilitar determinadas conductas anticompetitivas. Para introducirnos en el tema, el artículo comienza haciendo mención al concepto y utilidad del big data. Luego, hacemos referencia a la manera en que puede contribuir en la formación de barreras a la entrada o puede ser fuente de abuso de poder de mercado. El artículo continúa profundizando en la importancia de analizar el big data en las operaciones de concentración, especialmente en el caso de las killing acquisitions, tanto en los mercados digitales como en la industria en general. Al tratar las operaciones de concentración, el artículo se refiere a la dicusión sobre la carga de la prueba y los umbrales, en las fusiones preventivas. Finalmente, se aborda la posibilidad de que el big data pueda ser facilitador de colusión, permitiendo conductas como el pricing algorithms, por medio de algoritmos que pueden aprender a coludirse.
\end{abstract}

PALABRAS CLAVE Libre competencia, big data, barreras a la entrada, poder de mercado, concentración, colusión.

ABSTRACT In this article, we explain how big data presents new challenges beyond the protecting of privacy. Specifically, we discuss how it can affect competition in the markets, by facilitating certain anti-competitive behaviors. To introduce the subject, the article begins by mentioning the concept and usefulness of big data. Then, the article refers to how it can contribute to the formation of barriers to entry or can be a source of abuse of market power. The article continues delving into the importance of analyzing whether big data is a relevant asset in concentration operations, especially in the case of killing acquisitions, both in digital markets and in industry in general. When dealing with concentration operations, the article refers to the change on the burden of proof and thresholds in preventive mergers. Finally, the possibility that big data may be a col- 


\begin{abstract}
lusion facilitator is addressed, allowing behaviors such as pricing algorithms, through algorithms that can learn to collude.
\end{abstract}

KEYWORDS Competition Law, big data, barriers to entry, market power, concentration, collusion.

\title{
Introducción
}

Los avances tecnológicos de la era digital han producido muchos cambios, especialmente en la forma en que las personas nos relacionamos. Asimismo, tanto la forma de tomar decisiones como los nuevos modelos de negocios se han visto fuertemente influenciados por los adelantos digitales, como plataformas multilaterales y big data, entre otros. Sin embargo, desde el punto de vista legal, la preocupación por los datos ha sido enfrentada principalmente desde la protección de la privacidad, por lo que han quedado fuera del análisis algunas áreas relevantes, como la libre competencia (Stucke y Grunes, 2016: 51).

Asimismo, en la actualidad, es prácticamente inconcebible pensar en un modelo de negocios que no se relacione con alguna de las múltiples formas de usar, almacenar, analizar o distribuir datos. Es un hecho que nociones como las plataformas multilaterales, el big data, la inteligencia artificial, los algoritmos y el blockchain —entre muchos otros- llegaron y lo hicieron no solo para quedarse, sino también para guiar nuestros pasos en el presente y hacia el futuro (Stucke y Grunes, 2016: 116). Dado que la toma de decisiones se basa en la información disponible, en un mundo hiperconectado y dinámico es importante mantenerse actualizado y muy bien informado.

Por su parte, a través de los años, los mercados han cambiado. Lo han hecho complejizándose, globalizándose e interrelacionándose entre sí. Por esta razón, la regulación en materia de libre competencia ha debido modernizarse y actualizarse, con el objetivo, entre otros, de alcanzar la velocidad que el desarrollo tecnológico imprime al crecimiento económico.

Como hemos indicado, uno de los grandes cambios que han experimentado los mercados es la llegada del big data, que, en palabras simples, es la acumulación de grandes volúmenes de información. Esta agrupación de datos es posible principalmente gracias a las tecnologías de la información y las comunicaciones. En este contexto, entendemos que el big data es un conjunto de datos en volúmenes monumentales (Bruckner, 2018: 8). Por otra parte, gracias a la introducción de big analytics, este grupo de información se ha transformado en un activo de valor muy interesante, que permite que existan empresas cuyos modelos de negocios, sus decisiones y estrategias, se encuentren basadas en el big data (Zúñiga, 2019: 209).

No obstante, desde la perspectiva del análisis jurídico, la protección de la privaci- 
dad ha ocupado gran parte del debate relacionado con los datos. ${ }^{1}$ En cambio, el acceso o la acumulación de grandes volúmenes de datos no siempre fue una preocupación principal desde el punto de vista de la libre competencia. Este enfoque cambió en los últimos años, principalmente a partir del trabajo de Geradin y Kuschewsky (2013). ${ }^{2}$ Antes de ellos, los riesgos de la era digital fueron aceptados, tanto por los usuarios como por las autoridades, a cambio de ciertos beneficios considerados muy significativos para el bienestar de los consumidores, quienes entregaban sus datos aceptando la exposición que ello pueda implicar, o bien sin tener conocimiento efectivo de sus implicancias.

Sin embargo, en un mundo cada vez más digitalizado, la información ocupa un lugar absolutamente principal. El big data despertó el interés de quienes creemos que el mercado, adecuadamente regulado, es el mejor mecanismo para determinar los precios, y en consecuencia llevarnos hacia el bienestar económico y social. Desde el punto de vista de la libre competencia, se han planteado interrogantes frente al acceso y uso del big data, como la posibilidad de que la posesión de big data pueda permitir la configuración de monopolios, facilitar abuso de poder de mercado, la creación de barreras a la entrada, aumentar la concentración en los mercados y facilitar la colusión.

El éxito de algunas compañías ${ }^{3}$ y el constante aumento de su poder de mercado han contribuido a que el interés por estos temas aumente considerablemente en los últimos años. En este contexto, los objetivos de este artículo son preliminares, en el sentido de que este estudio busca identificar los escenarios en que tanto las legislaciones como las autoridades antimonopólicas ${ }^{4}$ deberían promover una regulación que permita sancionar como ilícito anticompetitivo los usos o abusos del big data cuando son en perjuicio de la competencia y, por ende, de los consumidores.

En consecuencia, el big data no solo plantea desafíos desde el punto de vista de la tecnología, sino también desde la perspectiva de la privacidad y la protección de datos, desde la perspectiva de los derechos del consumidor y de la defensa de la libre competencia. Sin embargo, el análisis de este artículo se restringe a repasar solamente los principales desafíos que el big data representa para la libre competencia. Teniendo ello en consideración, el objetivo que nos hemos propuesto es ofrecer una visión de las opiniones de los principales académicos y órganos de la competencia, con el fin

\footnotetext{
1. Sobre el particular, véase Frigerio (2018).

2. Luego del trabajo de Geradin y Kuschewsky (2013), se publicaron los artículos de Tucker y Wellford (2014) y de Lerner (2014). Todos ellos dieron origen a un debate más profundo sobre big data en materia de libre competencia.

3. A modo de ejemplo, podemos citar Facebook, Amazon, Google, Apple, Whatsapp, Uber e Instagram.

4. En Chile, esto es la Fiscalía Nacional Económica (FNE) y el Tribunal de Defensa de la Libre Competencia (TDLC).
} 
de entregar un resumen explicativo de los principales aspectos pro y anticompetitivos del big data.

Para cumplir con el objetivo planteado, primero introduciremos la noción de big data y sus características, para luego referirnos a los principales desafíos que presenta en materia de competencia. En este aspecto, específicamente, describiremos de qué manera el mayor volumen de datos contribuye tanto en la creación como en la participación de barreras a la entrada, abuso de poder de mercado, operaciones de concentración y colusión. Al tratar las operaciones de concentración, nos referiremos a la carga de la prueba y los umbrales en las fusiones preventivas, aspectos muy vigentes en la discusión internacional. Finalizaremos con las conclusiones de rigor.

En todo caso, cabe señalar que este artículo no pretende agotar las posibles soluciones a los casos planteados desde una perspectiva legal, sino que, por el contrario, nuestro objetivo no es más que estimular el debate en torno al big data, principalmente en Chile, desde la perspectiva de la libre competencia, dada la relevancia que tiene en el mundo actual y lo que significará en el futuro.

\section{Concepto de big data}

Big data es un concepto relativamente nuevo, por lo que no siempre hay claridad ni uniformidad en lo que su significado comprende. Esta afirmación es apoyada por Stucke y Grunes (2016: 15), entre otros, quienes sostienen que existen varias definiciones de big data, y muchas de ellas son generales e inclusivas. Por lo tanto, antes de analizar sus implicancias en materia de libre competencia, en los párrafos siguientes expondremos el sentido con el cual se ha utilizado en este artículo el término.

Como no hay una definición unívoca para el concepto de datos, ${ }^{5}$ tampoco existe en doctrina un concepto único para referirnos al big data (Bruckner, 2018: 7). No obstante, en general es posible decir que el término big data hace referencia a «gran cantidad y diversidad de datos útiles para el empleo de tecnologías digitales, así como las posibilidades de reunirlos y de que sean analizados y tratados» con muchos fines (Hoffmann-Riem, 2018: 41). Es decir, big data es la expresión que utilizamos para referirnos a cualquier conjunto de datos y de información, siempre que sea tan grande y complejo que no sea posible manejarlos por los métodos de análisis tradicionales.

Estos conjuntos de datos tienen determinados atributos que los hacen especiales. Estas características son su «velocidad, variedad y volumen» (Lasserre y Mundt, 2017: 89). Pero también es parte relevante del proceso mismo el conocer si la información obtenida es veraz, por lo que es necesario utilizar métodos cada vez más sofisticados

5. No obstante, en Chile el artículo 2 letra f) de la Ley 19.628 define datos de carácter personal o datos personales como «los relativos a cualquier información concerniente a personas naturales, identificadas o identificables». 
para obtener un análisis de calidad de los datos recolectados. Es por ello que la gran mayoría de los autores incorporan la veracidad dentro de las características del big data (Bundeskartellamt y Autorité de la Concurrence, 2016: 4; Stucke y Grunes, 2016: 16).

Sin embargo, es el valor de la información, es decir, su utilidad, lo que convierte al big data en un activo económico realmente interesante, cada vez más demandado por diversos actores del mercado. En otras palabras, la información debe tener un cierto grado de utilidad, puesto que, de lo contrario, no sería de interés para hacer un análisis jurídico y económico relevante. En todo caso, a pesar de que existen muchos datos, estos «no son bienes fungibles» (Rubinfeld y Gal, 2017: 342), dado que no todos los consumidores de datos están interesados en acceder a la misma información. Esto puede hacer variar su valor según quién los demande. Por ello, algunos autores agregan el valor como una quinta característica del big data (Hu y otros, 2014: 655).

Así, para efectos de este artículo, cuando hablamos de big data nos referimos a aquellas grandes cantidades de datos, de distintos tipos, que se producen a gran velocidad, que provienen de distintas fuentes, $\mathrm{y}$ «cuyo manejo y análisis requiere nuevos $\mathrm{y}$ potentes procesadores y algoritmos» (Bundeskartellamt y Autorité de la Concurrence, 2016: 4). Destacamos que no se incluye en el concepto de big data la uniformidad en el contenido de la información, la cual se opone a la variedad de contenidos. De esta manera, se permite que dentro de este gran volumen de datos pueda haber todo tipo de información, como preferencias de los consumidores, datos de desastres naturales, registro de velocidad, registro de ubicación, reacciones frente a estímulos, intención de voto en elecciones, etcétera.

En síntesis, entendemos incorporadas en el concepto de big data las cinco características enunciadas en esta sección, esto es, velocidad, variedad, volumen, veracidad y valor.

\section{Utilidad del big data}

Antes de proceder a examinar los desafíos que representa el acceso y posesión de big data en materia de libre competencia, para efectos de uniformar el criterio de análisis, es necesario referirnos a su capacidad y usos.

Existe evidencia que sugiere que el análisis del big data está conduciendo no solo el conocimiento y la innovación, sino que también afecta la forma en que se desarrollan y operan los mercados. ${ }^{6}$ Entre otras cosas, la irrupción del big data ha modificado

6. De acuerdo con la OCDE, el big data tendría gran potencial para introducir mejoras en los mercados y el mundo privado, para aumentar la eficiencia, la productividad, la competencia económica y el bienestar social. Asimismo, podría ayudar a enfrentar los desafíos propios del sector público, como cambio climático, desastres naturales, salud pública, agua, energía, seguridad, etcétera. Sobre el particular, véase OCDE (2015). 
la toma de decisiones y ha permitido mejoras en los productos mediante la introducción de cambios en los procesos productivos. Junto con ello, se han incentivado nuevos modelos de negocios, lo que ha permitido un incremento en la cantidad y un aumento en el nivel de los servicios, ligados también a desarrollos tecnológicos. En virtud de ello, el big data «recientemente, fue declarado como un nuevo y significativo activo que alimenta la economía de la información» (Rubinfeld y Gal, 2017: 341).

El modelo de negocios de muchas empresas que operan a través de internet comprende la recolección y el análisis de datos, los que se obtienen, principalmente, de quienes acceden a sus plataformas, es decir, de los usuarios de internet que entregan información relevante mientras hacen uso del contenido de las páginas o aplicaciones. En palabras de Macedo (2019: 289), «con el surgimiento de distintos servicios ofrecidos de manera digital, los usuarios se acostumbraron a obtener servicios gratuitos a cambio de brindar grandes cantidades de información personal a las empresas». Esta data se entrega mientras se navega en internet, puesto que cada clic que se hace en una plataforma demuestra interés por algo. En otras palabras, al hacer clic se produce información de las necesidades o conductas de los usuarios.

De esta manera, «los datos suministran información a partir de "huellas" que deja el usuario de internet, que, en el mundo de la tecnología, se suele conocer como clickstream data y que puede ser tratada posteriormente con diversas finalidades» (Navas, 2015: 33). De este modo, la cadena de valor del big data comienza con la recolección de datos por la plataforma, y consiste en las etapas de generación, adquisición, almacenamiento y análisis (Hu y otros, 2014: 681). La recolección de datos incluso permite generar «cadenas globales de valor» (OCDE, 2015: 23), lo que ocurre cuando la recopilación de información se produce no solo en un punto geográfico específico, sino en varios de ellos de manera simultánea, situación que hace que el valor de los datos sea aún mayor. Esto significa que quienes tienen acceso a big data se pueden beneficiar de información muy valiosa, la cual les otorga un poder de tal envergadura que les permite incluso influir en el mercado.

Ahora bien, el uso del big data puede llevar a influir en el mercado tanto desde el punto de vista de la oferta como de la demanda. De acuerdo con Macedo (2019: 289-291), esto ocurre a través de algoritmos, los que en principio permiten disminuir las asimetrías de información entre consumidores y proveedores. Por ejemplo, los consumidores pueden comparar los productos y cambiar de proveedor con gran facilidad, lo que lleva a los competidores a mejorar la oferta. Esto es, evidentemente, un beneficio para la competencia.

Sin embargo, es necesario seguir profundizando en este análisis. Algunos autores ven con claridad que los datos personales deben protegerse, no solo por el derecho a la privacidad y la seguridad de las personas, sino también porque constituyen un «bien económico» (Frigerio, 2018: 60). Como señala Navas (2017: 265), en el mercado digital ocurren transacciones normales como en cualquier otro mercado, y por ello quienes 
son consumidores de contenido digital obtienen el suministro que buscan a cambio de una contraprestación. Esta contraprestación es de carácter no pecuniario, y está formada por los datos personales que el consumidor acepta entregar al momento de descargar el contenido digital. De este modo, los datos personales pueden ser considerados como una moneda de cambio, incluso cuando su titular no es consciente del valor que éstos realmente tienen o de los derechos a su favor que de este hecho emanan.

Asimismo, los datos son un tipo de activo muy interesante, dado que son bienes no consumibles, por una parte, pero además pueden utilizarse en simultáneo por muchos usuarios, lo cual constituye una novedad si consideramos las características justamente opuestas de los insumos y de las materias primas en el proceso productivo tradicional. En cualquier caso, es importante destacar que, como señalan algunos autores, el valor de los datos depende de su contexto y se ve en especial afectado por su precisión y oportunidad (Schepp y Wambach, 2016: 121). Vale la pena señalar que este punto es controvertido. Así, al recoger las características principales que hacen que un bien sea económico - la rivalidad y la exclusividad-, Frigerio (2018: 60) distingue cuatro categorías de bienes económicos: privados, cuasi privados, cuasi públicos y públicos. Luego, la autora analiza el derecho a la privacidad como bien cuasi privado (no rivales, pero excluibles) y como bien público (no rivales, no excluyentes). En materia de competencia este análisis es relevante, ya que si el bien no es ni rival ni excluyente - características propias de los bienes privados-, entonces no pueden existir riesgos de competencia. ${ }^{7}$

Retomando lo señalado en cuanto a la cadena de valor del big data, nos referiremos al proceso de formación de valor, pues lograr generar big data de un valor realmente útil no es algo que ocurra solo. Es tanta la cantidad de información producida, que individualmente no somos capaces de dimensionarla y, por lo tanto, menos de analizarla. El proceso requiere colaboración, puesto que pretende conseguir los datos, reunirlos, analizarlos cuantitativamente y entregar conclusiones cualitativas. Cada una de estas etapas requiere de habilidades distintas. Dichas destrezas, sumadas a la experiencia que se adquiera con el tiempo, también le otorgará más valor al resultado. ${ }^{8}$

Como la recopilación de datos puede acarrear grandes beneficios, es muy probable que las compañías tiendan a economías de escalas y economías de alcance. Esta situación puede tener consecuencias indeseadas, como mercados altamente concen-

7. Sobre los datos como bien económico, véase Frigerio (2018: 60).

8. El sistema en el que conviven el big data con el proceso de toma de decisiones económicas y sociales está altamente conectado: proveedores de internet, servicios de tecnología de la información (como servicios de nube, software analítico, sistemas de gestión de bases de datos), oferentes y demandantes de datos (por ejemplo, consumidores, sector público, corredores de datos, bases de datos), analistas de datos, y, finalmente, emprendimientos de todo tipo, basados en los datos ya existentes, generados por ellos mismos o por terceros. 
trados, según se expondrá más adelante en este artículo. En contraste con lo anterior, el manejo de big data puede ser muy positivo, y ser significativo en la expansión del crecimiento de la productividad, por presentar beneficios tanto a nivel general como para un modelo de negocios determinado.

Ahora bien, desde el punto de vista del valor contractual, el precio de los datos dependerá principalmente de dos características: quién es su titular, es decir, si su dueño son las personas o empresas de big data; y el estado en que se encuentren, es decir, si han sido tratados o no. No obstante, desde la perspectiva de la legislación antimonopólica, nos interesa también su valoración en abstracto, es decir, aquélla «que se corresponde con el valor monetario de los datos personales, abstractamente considerados, en el mercado» (Navas, 2017: 270), por una parte, y las externalidades de red que producen las plataformas digitales, por la otra.

Como ya se mencionó, específicamente, lo que ha otorgado al big data la calidad de activo con valor en sí mismo y ha aumentado en forma significativa su valor es el surgimiento de big analytics (Ezrachi y Stucke, 2016: 15), que por lo general se entiende como la habilidad de diseñar algoritmos capaces de acceder y analizar gran cantidad de información. En virtud de que los datos pueden ser analizados, el big data es en sí mismo un bien económico, cuya utilización va más allá de los mercados digitales y tecnológicos, por lo que permite aumentar el bienestar económico de aquéllos que tienen acceso a la información generada. ${ }^{9}$ Esta mejora se produce porque a mayor cantidad de información disponible, es posible obtener una cantidad mayor de correlaciones. ${ }^{10}$ En un mercado, quien pueda hacer correlaciones en mayor volumen podrá también llegar a conclusiones más certeras y tomar decisiones con mayor precisión. Esto es así tanto en comparación con los competidores actuales como respecto de los potenciales. En efecto, mediante la identificación de las necesidades e intereses de gran cantidad y variedad de consumidores, es posible crear perfiles más sofisticados de clientes, que permiten, entre otras cosas, el «envío posterior de la publicidad "dirigida" online a ese destinatario a partir de un determinado perfil del mismo extraído sobre la base de la información que la cookie ha permitido tratar de su titular» (Navas, 2015: 33).

Siguiendo en la profundización de las razones por las cuales el big data es un activo de valor interesante, además de ser relevante en la toma de decisiones, respecto

9. Goldenberg $(2019: 7,27)$ propone avanzar en la línea de prevención y alivio del sobreendeudamiento de los consumidores financieros, por intermedio del préstamo responsable, en virtud del cual los productos y servicios financieros ofrecidos se ajusten al perfil y necesidades de cada consumidor, gracias a la utilización de avances tecnológicos, dentro de los cuales incluye al big data.

10. En la actualidad, al procesar la inmensa cantidad de información que se recolecta, se obtienen muchas correlaciones que antes no era posible ver. A través de estas correlaciones, que antes permanecían ocultas porque no era posible cruzar los datos, se puede obtener información sobre las preferencias de los clientes. Sobre este particular, véase Hoffman (2017). 
del bussiness plan de cada empresa, «los datos puedes ser utilizados como un input en la producción de bienes y servicios» (Matos, 2019: 328), al permitir que las empresas productoras de bienes y servicios entreguen productos de mejor calidad a sus clientes, toda vez que mientras más conocimiento tengan las compañías de la valorización que los consumidores dan a las características de los bienes y servicios, tendrán mayores posibilidades de dedicarse a optimizar esos atributos. En consecuencia, los productos puestos a disposición del público serán cada vez más atractivos, debido a que parecerá como si hubiesen sido especialmente creados para satisfacer las necesidades de los consumidores.

Como explican Schepp y Wambach (2016: 121), la recolección de datos puede llevar a mejorar en forma significativa los servicios; luego estos servicios pueden atraer a más usuarios, lo que permite a las compañías acceder a una mayor cantidad de datos. De esta manera se genera un efecto conocido como retroalimentación positiva (positive feedback loop). Cabe precisar que los feedback loops, tanto positivos como negativos, son efectos estructurales de los mercados de red, no efectos inherentes al big data. Sin embargo, es esta retroalimentación positiva, que a su vez representa economías de escala para las empresas (Matos, 2019: 341; Schepp y Wambach 2016: 121), la que puede acarrear consecuencias en materia de libre competencia, puesto que permite obtener poder de mercado, o bien contribuye a que los niveles de concentración económica sean mayores. El mismo efecto se producirá en virtud de las economías de alcance, en el caso de que una misma compañía ofrezca múltiples servicios que recolecten datos (Schepp y Wambach 2016: 121).

En conclusión, es necesario avanzar en estas materias para evitar los riesgos y costos que pueden generarse, ya sea por errores en aplicación de la ley o por vacíos legales. En cualquier caso, como señalan Bamberger y Lobel (2017: 1.053), al mirar la industria digital e intentar regular las conductas potencialmente perjudiciales en materia de libre competencia, es importante considerar los efectos positivos y negativos que esta industria pueda tener en la innovación, en los mercados, en los consumidores y en los trabajadores, es decir, el sistema económico en su totalidad.

\section{Big data en el análisis de la libre competencia}

Como es sabido, las normas sobre libre competencia buscan que los oferentes de bienes y servicios en un mercado determinado compitan libremente entre ellos, respetando las reglas que el marco regulatorio impone. Su objetivo final es la eficiencia en los mercados en armonía con el bienestar de los consumidores. ${ }^{11}$

Desde este punto de vista, el big data puede traer beneficios tanto para la com-

11. Felipe Irarrázabal, «El sistema chileno de defensa de la libre competencia», Fiscalía Nacional Económica, 2011, disponible en https://bit.ly/37av884. 
petencia como para los consumidores. ${ }^{12}$ Para algunos autores, las principales ventajas que ya ha aportado a la sociedad consisten en una gran cantidad de servicios y contenidos gratuitos para los usuarios de plataformas digitales, mejor calidad de los productos y aumento de la innovación (Sokol y Comerford, 2016: 3), todo lo cual se traduce en crecimiento económico.

No obstante, para algunos autores, «la información es un insumo valioso para ofrecer bienes y servicios de forma más eficiente» (Macedo, 2019: 289). Por lo tanto, desde que la cantidad de datos y el alcance que tienen las empresas para recolectarlos, almacenarlos, analizarlos y utilizarlos se ha comenzado a multiplicar por segundo, para autores como Sokol y Comerford (2016: 8) se ha vuelto evidente cómo el big data podría acarrear posibles perjuicios para la libre competencia en los mercados y, en consecuencia, para los consumidores. Siguiendo esta línea, el principal detrimento que podríamos observar es la pérdida en la calidad e innovación de los bienes y servicios. También puede llegar a verse menoscabada la privacidad de los consumidores, hasta incluso producir daños y perjuicios a ella.

Por su parte, existe evidencia de que han aumentado los ratios de concentración en algunos mercados, en los que además el big data ha comenzado a convertirse en una barrera a la entrada (Sokol y Comerford, 2016: 8-12). Por otra parte, una opinión contraria es la de Evans (2017: 36), para quien la evidencia histórica refuta la propuesta que considera al big data como una barrera a la entrada. Ello se sustenta en que, en términos generales y desde la perspectiva de la competencia, el big data no es un bien exclusivo, tiene múltiples sustitutos, su valor tiene muy corta duración porque los datos necesitan ser analizados para tener un valor interesante y, además, las plataformas son tan diferentes entre sí que requieren de datos muy diversos.

Por ello, en este artículo nos hemos planteado el objetivo de lograr un análisis comprensivo del big data, en cuanto éste puede llegar a afectar la libre competencia. Esta es la razón por la cual a continuación se expondrá la forma en que el big data podría interactuar con las principales conductas anticompetitivas, ya sea como causa o efecto.

\section{Conductas anticompetitivas y big data}

Como hemos indicado, procesar grandes volúmenes de datos ha generado efectos disruptivos en la vida de los seres humanos, tanto en el aspecto económico como en lo político y social. Las vidas de millones de personas se han visto transformadas por la llegada del mundo digital, al tiempo que han ido surgiendo nuevos modelos de negocios, por un lado, y nuevos modelos de consumo, por otro.

12. De acuerdo con Macedo (2019: 289), los consumidores obtienen gran cantidad de servicios en forma gratuita a cambio de entregar información personal a las empresas oferentes de servicios digitales. 
En cierta medida, este nuevo mundo representa múltiples oportunidades y grandes beneficios, toda vez que los avances tecnológicos "promueven una mayor competencia en los mercados, ampliando su tamaño e intensificando su rivalidad» (Macedo, 2019: 287).

Dado que los bienes jurídicos protegidos por la legislación en materia económica son el bienestar de los consumidores ${ }^{13} \mathrm{y}$ la eficiencia económica de los mercados, ${ }^{14} \mathrm{y}$ considerando que estos bienes jurídicos son los fundamentos normativos de la protección establecida en la legislación antimonopólica, ${ }^{15}$ se confirma la conveniencia de revisar los desafíos que el fenómeno del big data puede generar en materia de libre competencia. En el caso de Chile, esta hipótesis nace del bien jurídico mismo protegido por el artículo primero del Decreto Ley 211 de 1973, esto es, "promover y defender la libre competencia en los mercados».

Con el objeto de maximizar los beneficios que la era digital origina y de hacer frente a tiempo a los obstáculos que este nuevo mundo acarrea, ${ }^{16}$ la regulación económica debe ser debidamente analizada, con el objetivo de plantearse si es o no necesario regular también desde esta perspectiva los modelos de negocios propios de un mundo digitalizado. De esta manera, al estudiar cómo debe tratarse el big data en materia de libre competencia, debemos tomar en consideración todos los bienes jurídicos referidos.

Sin embargo, para efectos de este trabajo, hemos seguido la línea de Budnik (2019: 30), en el sentido de que «tomaremos como eje central de la protección del derecho de la libre competencia la noción de eficiencia económica». No obstante, cabe señalar que la eficiencia económica no es un fin en sí mismo, sino en cuanto sirve al estado de bienestar como medio o vehículo para alcanzar su bien jurídico final y general, que no es otro que el bienestar social, de donde nace la importancia de que el Estado pueda administrar los escasos recursos que obtiene de la manera más eficiente posi-

13. Ezrachi (2018: 4) sostiene que, en el contexto de la economía digital, un enfoque de la política de la competencia orientado principalmente hacia el bienestar del consumidor es beneficioso, puesto que permite, entre otras cosas, dirigir los esfuerzos hacia el bienestar de un mayor grupo de consumidores.

14. La eficiencia económica de los mercados considerada como motor del bienestar de la sociedad.

15. La protección de estos bienes jurídicos se traduce, entre otras cosas, en la confianza y credibilidad tanto en el mercado como en las instituciones. De ahí deriva la importancia y la necesidad de la constante búsqueda de tutela por parte de la legislación.

16. De acuerdo con la OCDE (2015), mientras las sociedades transitan hacia una economía basada en big data, las políticas públicas deberán enfrentar múltiples desafíos, entre los cuales destacan: incentivar infraestructura para el desarrollo tecnológico; promover una cultura orientada hacia el cambio en la obtención y manejo de la información, tanto en el sector público como en el privado; invertir en capacitación y entrenamiento para desarrollar las habilidades necesarias para enfrentar el cambio cultural; incentivar el flujo libre y transfronterizo de información; promover el uso responsable de los datos personales y una cultura de riesgos asociados a tecnologías digitales, para toda la sociedad; evaluar de manera correcta la concentración en los mercados y las barreras a la competencia. 
ble y al menor costo. ${ }^{17}$ En cualquier caso, los principios de una regulación económica eficiente sólo justifican la regulación cuando existen fallas de mercado. Dichas fallas «pueden clasificarse en: i) poder de mercado, ii) externalidades, iii) problemas de información, y iv) bienes públicos» (Macedo, 2019: 293).

Lo anterior supone también que quienes participan en el mercado cuenten con información para tomar las decisiones adecuadas a sus intereses, entre otras cosas, de modo que ninguna de las partes pueda influir en el mercado de manera artificial abusando de su poder en desmedro de la competencia.

Por cierto que el acceso, manejo y control del big data trae grandes posibilidades de desarrollo para la sociedad. Por otra parte, es una oportunidad de afectar las condiciones de las transacciones, es decir, de influir en el mercado, para obtener un mayor beneficio propio. Así, ello obliga a las autoridades a evaluar las políticas de libre competencia, para lo cual es esencial revisar las fallas de mercado que se pretende solucionar, y buscar una regulación idónea, adecuada y dinámica, de modo que no favorezca a los competidores actuales. Ahora bien, regular el acceso y uso del big data desde el punto de vista de la libre competencia es de interés sólo en cuanto dicho acceso pueda significar - aunque sea eventualmente - un atentado en su contra, que tienda a producir mayor concentración en los mercados o genere otros efectos anticompetitivos. Algunos autores han sostenido que si lo anterior no ocurre, no es necesario regular e intervenir, sino que se debe dejar que los usuarios gocen libremente de los beneficios del big data (Watson y Zoido, 2019: 417).

En virtud de las posibilidades que el big data presenta para afectar los mercados, en los capítulos siguientes expondremos cómo éste puede permitir el surgimiento de nuevas barreras a la entrada, por lo cual, según la OCDE (2015: 18), es necesario propender hacia «mejores definiciones del mercado relevante y la consideración de posibles perjuicios del consumidor debido a la violación de la privacidad». También expondremos la relación entre big data y poder de mercado. Luego, revisaremos cómo el big data puede permitir aumentos en los niveles de concentración de mercado. Terminaremos este capítulo refiriéndonos a una de las principales preocupaciones en estas materias, esto es, que los algoritmos se constituyan en facilitadores de colusión, al permitir prácticas concertadas que no eran posibles de imaginar antes de la época digital.

\section{Big data como barrera a la entrada}

La facilidad o dificultad para acceder a un mercado será uno de los factores que determinarán su competitividad. Esta es la razón por la cual la promoción de la com-

17. Cabe señalar la opinión de Accinelli y Salas (2019: 251), quienes consideran que «el estado de bienestar es en sí una intervención deliberada para regular las fuerzas del mercado». 
petencia busca, entre otras cosas, derribar las principales barreras de acceso a los mercados.

La identificación precisa de qué constituye una barrera a la entrada genera controversia entre los economistas. Para algunos, solo aquéllas impuestas por los Estados pueden ser consideradas barreras a la entrada propiamente tales. Para otros, constituye una barrera de acceso a un mercado cualquier costo de producción que un nuevo actor en el mercado debe incurrir, mientras que no debe ser incurrido por quienes ya forman parte del mercado. ${ }^{18}$ En opinión de Valdés (2006: 447), «los costos de entrada no se consideran una barrera en la medida que la entrada sea libre para cualquier competidor dispuesto a pagarlos y el monto de tal pago sea razonable». En el caso del big data, es posible identificar barreras a la entrada en la recolección, en el almacenamiento, en el análisis y en el uso de los datos. ${ }^{19}$

Un primer aspecto para tener presente al referirnos al big data como barrera a la entrada es el costo de instalación de una plataforma que permite recolectar datos. Bamberger y Lobel (2017: 1.056) sostienen que «por diseño, los costos de inicio para operar una plataforma digital son bajos: una aplicación sirve de mercado». En consecuencia, acceder al mundo del big data no es difícil, no requiere gran capital, lo que significa que, en términos generales, podemos decir que el big data no es una barrera a la entrada a los mercados. No obstante, es importante señalar que ello no impide que pueda convertirse en barrera a la entrada en virtud de los volúmenes o escalas necesarios de recolectar. En consecuencia, no puede establecerse como principio que el solo hecho de tener acceso a big data es un atentado contra la libre competencia, puesto que sin big analytics es difícil concebir un acto anticompetitivo. Pero lo que sí podemos presumir es que una compañía que posee la capacidad de generar big data tiene también la habilidad para invertir en algoritmos necesarios y en nuevas tecnologías que le permitan dar valor a los datos. De esta manera, obtendrá datos realmente útiles a sus intereses.

Ahora bien, si cambiamos el foco del análisis y miramos el big data como un insumo necesario para producir ciertos bienes y servicios, veremos que, como activo, puede constituir una barrera a la entrada a algunos mercados. Incluso acceder a los

18. Otros conceptos pueden considerarse barredas de entrada a los mercados. A modo de ejemplo, podemos citar las economías de escala, la teoría de los mercados disputados, los costos hundidos, los oligopolios, el abuso de posición dominante y la competencia estratégica. Véase Viscusi, Harrington y Vernon (2005: 170-182).

19. Como barreras a la entrada en la recolección de los datos, las más relevantes serían las barreras tecnológicas, las legales y las de comportamiento. Dentro de las barreras en el almacenamiento, los autores analizan la situación de la tecnología, costos de salida o cambios, y barreras legales. En el ámbito de las barreras de análisis, encontramos la compatibilidad de los datos y las herramientas de análisis. Y como barreras de uso, señalaremos las barreras tecnológicas, las legales y las de comportamiento. Sobre el particular, véase Rubinfeld y Gal (2017: 349-367). 
mercados digitales puede requerir contar con big data generado previamente. Ello es así porque en mercados como los referidos, el acceso a «la información es importante para competir» (Lasserre y Mundt, 2017: 90). Así, la posesión o el acceso al big data pueden constituirse en una barrera a la entrada (Schepp y Wambach 2016: 122), lo que afecta a algunos mercados más que a otros. Pero no solo en los mercados digitales veremos que el big data puede ser una barrera a la entrada, sino que, por el contrario, esta situación ocurrirá en todos aquellos casos en que los potenciales aspirantes a entrar a un mercado determinado no puedan recolectar antecedentes de naturaleza semejante a la de aquellos datos generados por quienes ya participan del mercado, ni obtenerlos de fuentes proveedoras de la información, como corredores o agentes de datos. De esta misma manera, el acceso al big data puede representar una diferencia entre competidores no solo potenciales, sino también actuales. En cualquier caso, de acuerdo con Schepp y Wambach (2016: 122), la oportunidad es un factor que puede limitar las eventuales ventajas competitivas que el acceso al big data puede entregar, ya que para competir se necesita tener información valiosa y relevante, más que grandes volúmenes de información. Por lo tanto, lo que se busca es generar capacidad de recolectar y analizar data altamente relevante y no la misma que ha obtenido la competencia.

En cuanto a si el big data representa una barrera a la entrada en los mercados digitales, en opinión de la Australian Competition and Consumer Commission (Sims, 2017: 62), existen considerables barreras a la entrada y a la expansión en los mercados de plataformas de búsqueda y de redes sociales, en los que participan Google y Facebook, quienes tienen fuerte poder de mercado. De acuerdo con los resultados del estudio elaborado por dicha autoridad de la competencia (ACCC, 2019: 62), existen barreras de entrada y a la expansión - en los mercados mencionados- que surgen de los efectos de red, de uno y de dos lados, de marca, de inercia del consumidor, de costos de cambio, de economías de escala y de costos hundidos.

Para ilustrar lo expuesto hasta aquí, podemos tomar como ejemplo el caso de Uber. Como es sabido, el modelo de negocio de esta plataforma consiste en conectar choferes con pasajeros a través de una aplicación. Bamberger y Lobel (2017: 1.057) consideran que Uber es una plataforma tecnológica y no una empresa de taxis, razón por la cual no se le aplicarían las reglas propias del servicio de transporte. De esta manera, Uber ha podido cruzar las barreras a la entrada que históricamente han imperado en el mercado de taxis, las cuales existen prácticamente en todo el mundo. Lo interesante de este caso es que «la fuerza de la plataforma de Uber es que opera en un nuevo segmento de mercado, pero compite directamente con segmentos existentes» (Bamberger y Lobel, 2017: 1.057). Es decir, Uber opera en el mercado digital, al ser una plataforma tecnológica, pero compite en el mercado de transporte. Es en este último mercado donde Uber produjo cambios importantes. Algunos de éstos han sido positivos para el bienestar económico. Dentro de los beneficios sociales que Uber ha 
generado podemos destacar la mayor oferta de transporte a menor precio y la fuente de trabajo flexible. Algunos autores incluso destacan que Uber ha desafiado «carteles largamente atrincherados» (Bamberger y Lobel, 2017: 1.057), con lo que insinúan que, en algunos lugares del mundo, el gremio de taxistas es muy poderoso y ejerce un lobby muy fuerte. Ahora bien, el éxito de Uber radica en utilizar datos de sus usuarios de manera inteligente. A través de los sistemas que contiene su plataforma, la empresa recoge big data en forma constante, el que «se representa mediante informes internos, pero también permite a Uber predecir determinados comportamientos o situaciones y reaccionar, actuar y adaptarse en tiempo real». ${ }^{20}$ En otras palabras, generar datos en gran volumen y analizarlos rápidamente ha permitido a Uber replantearse el modelo de negocio, expandirse y aumentar su posición en el mercado.

A partir de la argumentación precedente, está claro que es difícil aislar los fenómenos y observarlos desde un solo punto de vista, puesto que al hacerlo con seguridad se cometerán errores. Por ejemplo, si observamos el caso de Uber únicamente desde la perspectiva de la libre competencia, podríamos concluir que la autoridad de la competencia no debe permitir que se transforme en una barrera a la entrada ni que abuse de su poder de mercado. No obstante, dejar de lado los beneficios sociales de Uber sería, a nuestro juicio, un error. En consecuencia, la forma tradicional en que se ha concebido la protección de la libre competencia parece no ser suficiente para regular de manera adecuada los efectos del big data.

Por otro lado, es conveniente destacar que, a pesar de que la legislación parece no ser suficiente para regular los efectos del big data en los mercados, ya en el año 2008 el Tribunal de Defensa de la Libre Competencia chileno, al resolver la consulta sobre la fusión entre Falabella y D\&S (Resolución 24/2008), sentó las bases para sostener que las sinergias de información generadas en virtud del big data constituyen una barrera a la entrada al mercado. ${ }^{21}$

\section{Abuso de posición dominante y big data}

Ya hemos identificado como un factor importante a considerar la oportunidad en la producción de la información, puesto que podría limitar las ventajas competitivas del big data (Schepp y Wambach, 2016: 122). Es decir, para un análisis adecuado y

20. «Uber y big data: Secretos del éxito de las VTC que transforman el transporte», Tech Week, 11 de febrero de 2019, disponible en https://bit.ly/3h2thGT.

21. La parte relevante del párrafo 48 de la Resolución 24/2008 del Tribunal de Defensa de la Libre Competencia señala lo siguiente: «Este es sin duda el caso de lo que se podría denominar como "sinergias de información", asociadas al desarrollo de bases de datos sobre los patrones de consumo y endeudamiento, mediante tarjetas no bancarias y programas de fidelización, de los clientes del retail integrado. Esta información permite perfeccionar las estrategias de comercialización y de competencia respecto de otros operadores del retail». 
realmente útil de los datos, no es solo necesario poseer gran cantidad de información, sino que ésta debe ser actual, adecuada y llegar a tiempo. De lo contrario, será inútil contar con ella. Por ello, no basta con que una empresa sea capaz de acceder a los datos, ya sea porque puede producirlos o porque puede adquirirlos en gran volumen de alguna fuente externa, sino que es necesario que pueda obtener un análisis en tiempo, forma y de utilidad para sus necesidades. ${ }^{22}$ En otras palabras, no basta con la cantidad de datos, sino que es necesario poder extraer de ellos información y conocimiento que permita hacer las correlaciones necesarias para tomar decisiones económicas.

Además, si bien es cierto que tanto las economías de escala como las de alcance, como los efectos de red directos e indirectos, pueden producir tipping en los mercados, es decir, pueden conducirnos hacia mercados más concentrados (Schepp y Wambach 2016: 122), también es importante reconocer que ello no es necesariamente un problema de poder de mercado, y menos de abuso de posición dominante. ${ }^{23}$ Por ello, tener acceso o hacer uso del big data disponible no es un problema en sí mismo.

Dado los fenómenos descritos, es conveniente señalar qué entenderemos por poder de mercado para efectos del presente artículo. Ciertamente, podemos encontrar muchas definiciones de poder de mercado en la literatura. No obstante, en términos generales, los autores coinciden en que existe poder de mercado «cuando una empresa puede fijar sus precios (o cualquier otra variable de competencia) por encima del nivel de competencia, de manera rentable y sostenida en el tiempo» (Cruz, 2019: 105). Es decir, la posición dominante ocurre en aquellos casos en que una empresa se comporta, para un determinado tipo de producto o servicio, como si fuera el único oferente dentro del mercado nacional. También nos encontramos frente a poder de mercado cuando, sin ser necesariamente la única, la compañía no está expuesta a una competencia efectiva, de modo que tiene el poder de actuar de forma independiente, sin considerar a sus competidores, lo que incide de manera sustancial sobre las decisiones de los otros partícipes del mercado. En definitiva, quienes tienen poder de

22. Esto es especialmente cierto para los servicios que operan como plataformas multilaterales y servicios basados en datos (Schepp y Wambach, 2016: 122). De acuerdo con Katz y Sallet (2018: 2.149), las plataformas multilaterales son empresas en que los efectos de redes se producen a lo menos en una dirección, mientras que la empresa facilita las interacciones entre dos o más grupos de usuarios, por lo que pueden establecer precios diferentes a distintos grupos de usuarios, en virtud del poder de mercado que la empresa detenta respecto de estos grupos.

23. Cabe señalar que, de acuerdo con Macedo (2019: 298), un caso distinto es aquel en que los efectos de red son muy fuertes. En tales casos, para evaluar de manera correcta el poder de mercado es necesario evaluar la naturaleza de los mercados de dos o más lados. Para ello se analizan todos los lados involucrados, y luego se estudia la retroalimentación que exista entre los lados involucrados. En opinión de Stucke y Grunes (2016: 156), solo un análisis comprensivo e integrado permitirá conocer en realidad el mercado relevante y el poder que las empresas competidoras detentan en él. 
mercado pueden alterar el equilibrio propio sobre el cual descansa el sistema, haciendo mal uso de su poder.

Es por ello que en los mercados, una vez que una empresa logra una determinada posición, es normal ver que intente mejorarla, o al menos mantenerla. Para ello, recurrirá a alternativas como la fusión o adquisición de nuevas compañías, lo cual genera los efectos económicos propios de una operación de integración horizontal o vertical.

En la actualidad, se ha incorporado como beneficio de un modelo de negocio integrado el que se pueda recolectar y analizar los datos provenientes de diferentes unidades, filiales o subsidiarias. Lo dicho aumenta el interés por buscar mecanismos de integración, en formas tanto horizontales como verticales. La integración horizontal -es decir, entre competidores- generará eventualmente un poder de mercado mayor. En el caso de los mercados digitales, también pueden existir riesgos en integración a nivel vertical. Ello es especialmente evidente en el caso de adquisiciones de startups tecnológicas (Bryan y Hovenkamp, 2020: 339). Este poder de mercado mayor puede ser lícito desde el punto de vista de la libre competencia. De acuerdo con Valdés (2006: 545), «aquél puede ser el resultado de una legítima eficiencia ganada por un competidor que ha logrado reducir sus costos y comercializar bienes de calidad superior a la de sus competidores».

Ahora bien, como hemos indicado, el beneficio logrado es también una ventaja competitiva, si consideramos que una compañía puede recoger datos personales de primera fuente - es decir, directamente del titular - en un volumen considerable, para luego tratarlos y analizarlos. Asimismo, la empresa tiene la posibilidad de combinar esta información y lograr mayores conexiones y correlaciones, para crear perfiles de consumidores más sofisticados. Si esta ventaja ha sido alcanzada de manera legítima, y permite hacer los mercados más eficientes, no presentará ningún problema desde el punto de vista de la competencia.

Sin embargo, es probable que las compañías que logran esta ventaja no tengan intención alguna de poner a disposición del mercado esta información, menos de compartir sus conocimientos con sus competidores, salvo que reciban un precio realmente alto a cambio. ${ }^{24}$ En definitiva, han creado o adquirido un bien, de valor económico considerable, y pueden intentar abusar del poder que dicho bien les proporciona. Por ejemplo, puede utilizarse el big data para inflar los precios respecto de ciertos destinatarios específicos de bienes o servicios (discriminación de precios). También es posible que el big data sea una fuente de información para los proveedores, que les permita discriminar entre consumidores por razones como ingresos, salud, nivel de educación, etcétera (Sims, 2019). Además de los ejemplos indicados, en opinión de Zúñiga (2019: 218), el big data podría ser fuente de abuso de posición de mercado cuando a

24. En consecuencia, aumenta su posición en el mercado, y al mismo tiempo se convierte en una barrera a la entrada. 
través de éste los proveedores incurren en conductas como las ventas atadas y autoposicionamiento mediante la discriminación que el big data les permite conseguir.

Por su parte, el Tribunal de Defensa de la Libre Competencia chileno constató, en el caso de la frustrada fusión entre Falabella y D\&S, algunas posibles fuentes de poder de mercado vinculadas a la concentración de datos. Dentro de dichas posibles fuentes destacan:

La posibilidad de desarrollar bases de datos sobre patrones de consumo, difícilmente replicables por competidores que operen a escalas menores y con más bajos grados de integración entre distintos negocios de retail, [...] la posibilidad concreta de desarrollar estrategias de ventas atadas, utilizando los distintos segmentos de retail bajo control de un mismo operador integrado, desincentivando así la compra de ofertas de competidores que operen a menores escalas y con un menor nivel de integración, [...] la capacidad de beneficiarse de diversas y significativas economías de escala y ámbito [y] la capacidad competitiva para expandirse hacia diversos nichos y formatos de competencia, sujetos a ámbitos locales de influencia, lo que produce un efecto disuasivo a la entrada, o futura expansión, de rivales con más bajos grados de diversificación en el retail y con volúmenes más pequeños de operación. ${ }^{25}$

En nuestra opinión, con esta resolución, el Tribunal chileno contribuyó a un debate - en ese entonces- incipiente.

\section{Big data y operaciones de concentración}

De acuerdo con Bravo y otros (2017: 97), «las empresas de menor tamaño cumplen un rol fundamental en el crecimiento de la economía por su impacto en el empleo y su rol de inclusión social». Por otra parte, la concentración en los mercados es potencialmente negativa para este tipo de empresas. ${ }^{26}$ En cambio, y desde el punto de vista del crecimiento económico, las operaciones de concentración pueden ser necesarias, y por tanto producir efectos positivos en los países. Las empresas pueden aprovechar sinergias, disminuir costos y traspasarse información valiosa entre ellas, lo que las vuelve más eficientes.

Sin embargo, para que se logren producir efectos auténticos en el crecimiento económico, las bondades de la concentración deben traspasarse a los consumidores.

25. Resolución 24/2008, Tribunal de Defensa de la Libre Competencia, 31 de enero de 2018, pp. 94-95, disponible en https://bit.ly/2BDeDpn.

26. De acuerdo con Bravo y otros (2017: 97-98), «en general, es notorio que las empresas de menor tamaño, pese a muchas veces producir bienes y servicios innovadores y de buena calidad, no tienen la opción de acceder a los canales de comercialización debido a que las grandes empresas obstaculizan el surgimiento de este tipo de competidores». En la misma línea, destacan cómo «las pymes deben lidiar con situaciones de abuso tales como retraso en los plazos de pagos a proveedores pyme». 
Es decir, la disminución de costos debe verse reflejada en una disminución de los precios que los demandantes finales de los productos pagan por ellos. Es por esto que, como señalan Schepp y Wambach (2016: 123), al controlar fusiones, la autoridad de defensa de la libre competencia debe prestar atención al fin estratégico de estas operaciones, dado que su objetivo puede ser adquirir u obtener mejor acceso a mayor número de datos, que luego puedan vincularse con conjuntos de datos ya existentes, lo que aumentaría las barreras a la entrada. Esto se aplica tanto a las fusiones horizontales como a las verticales, ya que el acceso a fuentes de datos más diversificadas puede fortalecer las economías de escala tanto como las de alcance, y mejorar la calidad de la información recopilada en general.

Las operaciones de concentración pueden presentar riesgos desde el punto de vista de la competencia. En primer lugar, la preocupación por la concentración radica en que existe evidencia de que, en los mercados con altos índices de concentración, los resultados operacionales son más altos. ${ }^{27}$ Por ende, los precios de los bienes y servicios tienden, a su vez, a subir. Asimismo, tanto las economías de escala como las de alcance, así como los efectos de red directos e indirectos, potencialmente llevan a niveles altos de concentración en los mercados. La especialización del trabajo y de la tecnología puede llevar a variaciones en el costo marginal, lo que disminuye el costo total de producción al producir más unidades y permite modelos de negocios cada vez más integrados y rentables. Es por estas razones que la autoridad de defensa de la libre competencia revisa los efectos de las operaciones de concentración, idealmente de manera preventiva, con el objeto de analizar si es necesario prohibirla o mitigarla.

Para saber con exactitud si un mercado es concentrado o no, antes es necesario definir con claridad los límites del mercado específico, estableciendo el mercado relevante caso a caso. Una vez determinado ello, es posible establecer las cuotas de mercado de cada empresa, y utilizar alguno de los índices de concentración para analizar el nivel de concentración de la industria. No obstante, en el mundo digital, el mercado relevante puede resultar difícil de definir, en especial si consideramos que dentro del concepto de mercado relevante debemos incluir los bienes «sustitutos suficientemente próximos» ${ }^{28}$ Es difícil medir la real dimensión de los mercados en los que participa el big data, dado que constantemente van produciéndose más y más datos en el mundo, y van surgiendo nuevos desarrollos tecnológicos impulsados por los datos y la economía digital, como ya hemos señalado. Además, un mismo grupo de datos puede producirse, comprarse o venderse en simultáneo en múltiples lugares. Según Stucke y Grunes (2016: 40), son las características de velocidad, variedad y

27. Para ejemplos, véase Viscusi, Harrington y Vernon (2005: 161).

28. «Guía para el análisis de operaciones de concentración», Fiscalía Nacional Económica, octubre de 2012, p. 10, disponible en https://bit.ly/2Us4jYa. 
volumen del big data, a las cuales hemos hecho referencia en la primera parte de este artículo, las que hacen aún más difícil, casi imposible, esta tarea.

Así, delimitar e intentar definir el mercado relevante de los mercados digitales en que el big data tiene un valor importante representa un gran desafío para la autoridad en materia de libre competencia, por la forma misma de ser de este mercado, por la gran cantidad de «servicios que se proporcionan de forma gratuita» y por los «efectos de red directos e indirectos» (Lasserre y Mundt, 2017: 95).

Por otra parte, aun cuando el big data por sí solo puede que no sea el factor determinante para afectar la competencia en los mercados, sí puede ser un punto de unión entre plataformas digitales $y$, por lo tanto, aumentar la concentración en estos mercados, con lo que hace crecer la posición de las compañías que participan en ellos.

Por esta razón es que la situación del big data debe ser revisada cuando se producen operaciones de concentración, tanto horizontales como verticales, específicamente en el caso de aquellas fusiones o adquisiciones que puedan tener como único objetivo el acceso a datasets preexistentes, producidos por las compañías adquiridas o absorbidas. ${ }^{29}$

Un segundo riesgo que se debe considerar en el análisis, en el contexto de operaciones de concentración, es que al existir múltiples partícipes en un proceso productivo, como generalmente es el proceso de producción del big data, y en la medida que el ecosistema va creciendo, también aumenta la cantidad de información circulando, y se multiplica el número de emprendimientos vinculados con el big data. Es de público conocimiento que pequeños emprendimientos tecnológicos pueden entrar en el mercado y competir con las compañías ya establecidas, y que existen en el mundo muchas startups ligadas al mercado de los datos. Incluso es sabido que estos emprendimientos han logrado desafiar a las grandes empresas, llevándolas constantemente a seguir desarrollándose. Ahora bien, las grandes empresas también disponen de la capacidad económica para monitorear el mercado, de manera de saber exactamente cuándo adquirir, invertir, fusionarse o tomar el control de estos nuevos desarrollos. Por lo general estos procesos, denominados killing acquisitions, ocurren antes de que las startups alcancen un tamaño relevante en el mercado y se conviertan en competidores reales. Así, las grandes compañías se comportan como depredadores de emprendimientos tecnológicos, eliminando cualquier potencial amenaza.

Por último, un tercer aspecto por considerar en este análisis — es decir, en el con-

29. No obstante, es necesario analizar el efecto que se produce caso a caso, en especial en el tema de las fusiones horizontales, o bien de fusiones verticales entre empresas relacionadas, dado que si el objetivo perseguido con tales operaciones es el de lograr sinergias y economías de escalas o de alcance, y éste produce un beneficio mayor en el mercado que el de generar concentración en el mercado por la integración del big data, no debería considerarse como un efecto negativo para la competencia, sino todo lo contrario. 
texto de operaciones de concentración- es la opinión de Sims (2017), en cuanto a que la autoridad de la competencia debe revisar con mayor cuidado aquellas operaciones en que las partes involucradas se dedican a recolectar o vender datos, o bien si están integradas verticalmente en la cadena de valor del big data. Así, si una fusión plantea problemas de competencia debido a la acumulación o combinación de diferentes conjuntos de datos, se debe pensar en remedios que aborden de manera adecuada el problema en cuestión. Schepp y Wambach (2016: 123) proponen una posible solución para algunos mercados basados en datos, la cual consistiría en exigir una duplicación de los datos y, por lo tanto, permitir a los competidores tener acceso a ellos..$^{30}$

A pesar de lo descrito, no puede considerarse a priori que una operación de concentración afectará la libre competencia. La velocidad con que se producen los cambios en la era digital permite que a cada momento se observen nuevos emprendimientos en este mercado. Sin embargo, para lograr que el equilibrio competitivo se mantenga constante en el tiempo, es necesario dotar a la autoridad correspondiente de las herramientas necesarias para permanecer alertas ante eventuales riesgos, y así analizar cada caso. ${ }^{31}$ Lo relevante será determinar si, una vez que se haya producido la concentración, quedará suficiente data disponible y accesible para los demás competidores, para los actuales y potenciales. ${ }^{32}$ Esto deberá definirse caso a caso.

Sin embargo, es importante considerar la necesidad de distinguir entre eventuales medidas de mitigación que se puedan aplicar en un caso particular, de otras formas de evitar distorsiones entre competidores en los mercados. Por ejemplo, de acuerdo con Schepp y Wambach (2016: 123), algunos autores consideran que es esencial facilitar la entrada a los mercados para que éstos vuelvan a ser competitivos, estableciendo una condición de igualdad entre competidores. ${ }^{33}$ Para ello, proponen establecer una obligación legal de dar acceso al big data que sea considerado esencial para competir. Junto con los problemas de privacidad de los datos que los mismos autores señalan (Schepp y Wambach, 2016: 124), es importante considerar que, en general, los competidores no necesariamente tienen conocimiento del big data que existe, por lo que menos podrían saber que se encuentran en desventaja desde el punto de vista competitivo.

Sin duda, la autoridad de la competencia debe fortalecer su rol preventivo en ma-

30. La propuesta de Schepp y Wambach tiene inconvenientes relacionados con la privacidad de los datos, los cuales los mismos autores ponen en consideración. Sobre el particular, véase Schepp y Wambach (2016: 124).

31. Sobre el particular, véase Stucke y Grunes (2016: 217).

32. En principio parece difícil considerar que los datos sean un bien escaso. Por ello, la pregunta adecuada es si las personas tienen acceso al big data en iguales condiciones. Véase Lasserre y Mundt (2017: 97).

33. Estos autores se basan en la doctrina de las facilidades esenciales para intentar sostener su postura. Véase Schepp y Wambach (2016: 123). 
teria de operaciones de concentración de empresas vinculadas al big data, en especial en mercados digitales multilaterales (Matos, 2019: 343). Pero la información en circulación y de dominio público será poca, cuando se trate de nueva competencia en el mercado. Ello hará más difícil hacer una evaluación preventiva de manera adecuada $\mathrm{y}$ asertiva.

En consecuencia, es necesario buscar un planteamiento específico para los casos de big data, propuesta que reconozca la especial naturaleza de este particular mercado. Una alternativa a la propuesta de Schepp y Wambach de establecer una obligación legal de acceso al big data es la señalada por Matos (2019: 344), y consiste en revertir la carga de prueba en las fusiones preventivas. De acuerdo con el Stigler Center (2019: 12), cuando una operación de concentración incluye una plataforma dominante, debería revertirse la carga de la prueba, es decir, imponer a la compañía la carga de probar que la operación no dañará la competencia.

En cualquier caso, es importante señalar que la propuesta de revertir la carga de la prueba no está libre de controversia. Según Johnston, ${ }^{34}$ dos argumentos principales se destacan en este debate. En primer lugar, tanto Estados Unidos como los países miembros de la Unión Europea tienen una larga historia de considerar justo mantener la carga de la prueba en la Fiscalía, por considerar que el cambio acarrea peligros desde el punto de vista de los precedentes en materia criminal. En segundo lugar, la duda se plantea respecto de la extensión de revertir la carga de la prueba, pues se teme un efecto dominó. Este efecto ocurriría toda vez que, en principio, revertir la carga de la prueba se ha planteado solo respecto de los mercados digitales, pero no está claro qué pasaría en los casos de mercados mixtos, ni menos si la iniciativa podría instalarse en otras industrias. En cualquier caso, es importante tener presente que esta discusión no está zanjada, sino todo lo contrario.

Otra alternativa a la de establecer una obligación legal de acceso al big data consiste en determinar la obligación legal de solicitar autorización previa en algunos mercados específicos, o en el caso de que una de las partes de la operación sea una startup tecnológica, independiente de los umbrales establecidos para la generalidad de los casos. Ello, con el objetivo de evitar que en mercados considerados esenciales para el funcionamiento de la economía y el bienestar social - como el farmacéutico o salud (Matos, 2019: 343), o como el financiero (Stucke y Grunes, 2016: 247)—, las operaciones de concentración no sean fiscalizadas adecuada y oportunamente, por quedar bajo los umbrales. En este sentido, el Stigler Center (2019: 12) propone que se modifiquen los umbrales, y que éstos se basen en criterios que permitan a la autoridad revisar la operación. Lo anterior se fundamenta en que, en mercados con fuertes tendencias a la monopolización, un error en la aprobación de una operación

34. Ryan Johnston, "Antitrust law and digital markets: Who has the burden of proof?», Disruptive Competition Project, 27 de noviembre de 2019, disponible en https://bit.ly/3cLyyPX. 
de concentración puede condenar a una industria al monopolio, y si se suma poder político, el error puede ser irreversible.

\section{Colusión en la era del big data}

Mientras más principios del modelo de competencia perfecta se respeten en un mercado, más competitivo éste será. En cambio, los agentes económicos que se coluden contribuyen a que al menos dos principios básicos del modelo de competencia perfecta desaparezcan automáticamente. Estos principios son la libertad para tomar decisiones y la atomicidad de la oferta y la demanda. El atentado contra ambos genera gravísimas consecuencias, sobre todo en los precios y en la calidad de los productos. También produce efectos en la cantidad de la oferta. Por ello, en términos generales, es aceptado que la colusión lleva a malos resultados económicos para la sociedad.

Así, «cuando empresas rivales se coluden y actúan como una sola entidad, generan utilidades extraordinarias a costo del bienestar social» (Budnik, 2019: 37). Es decir, cuando compañías competidoras suben sus precios previo acuerdo, los consumidores finales pagan dichos precios, por lo que toman decisiones económicas básicas como dejar de consumir otros bienes, endeudarse, etcétera. Lo señalado lleva a que, en definitiva, el costo de vida y del bienestar social de aquellos consumidores finales sea más alto, mientras que aumenta el margen operacional de las empresas coludidas. Es por esta razón que la legislación busca desenmascarar a quienes se coluden y sancionarlos con todo el rigor de la ley, puesto que, como lo que está en juego es el bienestar de la sociedad, la pérdida social neta es muy alta como para tolerar tales conductas. Lo que es dañino en términos generales, lo es también en la era del big data.

Algunos autores sostienen que en los mercados digitales el big data puede actuar como «un facilitador de la colusión y, lo que es peor, puede permitir nuevas formas de coordinación no posibles antes» (Macedo, 2019: 297). Por ello, se hace necesario identificar conductas ilícitas que podrían enmarcarse dentro de la actual legislación de defensa de la libre competencia, para diferenciarlas de aquéllas que quedarían impunes por no estar comprendidas dentro del tipo legal. Es importante precisar que en ningún caso será fácil para la autoridad, puesto que el primer desafío es comprender la tecnología misma, y hasta dónde ella puede ser facilitadora de colusión. ${ }^{35}$

Principalmente, el big data puede favorecer nuevas formas de colusión a través de algoritmos para la fijación de precios (pricing algorithms). En estos casos será difícil establecer un límite entre lo que es y lo que no es un acto que deba ser sancionado.

Ezrachi y Stucke (2016: 39) identifican los escenarios en que se puede configurar

35. Sobre cómo el intercambio de información y la comunicación pueden facilitar la colusión, véase Watson y Zoido (2019: 415). 
el delito de colusión a través del big data. En primer lugar, señalan los casos en que el delito se configura en forma expresa. En ellos, estamos bajo el tipo clásico de colusión, por lo que no representa novedad para nuestro análisis y queda cubierto por las legislaciones correspondientes. Los autores han denominado a esta situación el messenger scenario, puesto que la colusión ocurre entre personas naturales, o bien, entre personas jurídicas debidamente representadas, y el big data opera derechamente como un mensajero, el cual solo actúa como intermediario de información entre dos personas.

De acuerdo con los autores, el big data también bien puede utilizarse en una colusión tipo hub \& spoke, en la que se utiliza el algoritmo como el centro para coordinar la actividad de los competidores (Ezrachi y Stucke, 2016: 46). Este tipo de colusión, aun cuando más novedosa que la descrita en el párrafo anterior, de igual manera queda cubierta por la gran mayoría de las legislaciones pertinentes, por lo que tampoco representa un problema para este estudio.

Sin embargo, ocurre justamente lo contrario con los casos de colusión tácita. Ésta implica que no exista ningún tipo de acuerdo expreso entre los competidores involucrados, pero requiere confianza en que la competencia actuará de la misma manera, por una parte, e incentivos para mantenerse en el acuerdo tácito en el tiempo. Para que ello exista y perdure, es necesaria transparencia en la información entre los partícipes (Watson y Zoido, 2019: 415). En virtud del big data y su uso mediante algoritmos especializados, ${ }^{36}$ aumentan las posibilidades de estos casos de colusión, es decir, de nuevas formas de acuerdos, sin mediar acuerdos expresos entre competidores. Ezrachi y Stucke (2016: 56) han denominado a estos casos «el agente predecible» (the predictable agent), toda vez que hoy es posible contar con programas que hacen seguimiento de los precios de la competencia, que envían reportes de mercado, incluso que alertan de manera inmediata de cada cambio que se genere en la industria. Así, basta con crear o adquirir «algoritmos que ajusten los precios de acuerdo a los datos del mercado» (Macedo, 2019: 298), de modo que sin necesidad de mediar un acuerdo expreso previo entre competidores, los precios se pueden ajustar de forma paralela y simultánea, gracias a la cantidad de información existente.

Ahora bien, es en este último caso, el de la colusión tácita, en que la autoridad antimonopólica deberá enfrentar los mayores desafíos para combatir eventuales carteles originados a partir del big data. Para ello, dicha autoridad debe buscar formas de reducir las ventajas de estar coludido, por una parte, y de aumentar las sanciones asociadas a tales conductas, por la otra.

Harrington (2017: 650) coincide con quienes piensan que el big data puede ser fuente de nuevas formas de colusión, a través de pricing algorithms. Sin embargo, es claro al señalar que no siempre el resultado en los precios proviene de una interde-

36. Sobre colusión tácita y algoritmos, véase Beneke y Mackenrodt (2018: 110). 
pendencia ilegítima entre competidores, o entre los algoritmos de los competidores. Por ello, distingue entre algoritmos capaces de coludirse porque han sido programados para ello, y algoritmos que aprenden a coludirse (Harrington, 2017: 650).

Por su parte, también Sims (2017) ha señalado sus preocupaciones en materia de colusión, respecto de aquellos algoritmos que son capaces de aprender, al sostener que éstos podrían involucrarse en prácticas concertadas sin contravenir la legislación pertinente. No obstante, es interesante observar la legislación australiana correspondiente, la sección 45 de la Competition and Consumer Act, que sanciona las prácticas y acuerdos ya sea que tengan el propósito, produzcan el efecto o probablemente produzcan el efecto de disminuir en forma sustancial la competencia en el mercado. De esta manera, bastaría con que un determinado algoritmo tuviera realmente el potencial de aprender a coludirse, para que la empresa que lo implementa fuere responsable bajo la legislación australiana. Esto estaría en línea con las palabras de Sims (2017), para quien sostener «mi robot lo hizo» no basta para evitar la responsabilidad.

Por otra parte, debemos señalar que hay autores que no conciben el big data como facilitador de colusión. Ezrachi y Stucke (2020: 241) los llaman «escépticos», ya que, para aquéllos, esta conducta anticompetitiva sólo puede darse y sostenerse en el tiempo por medio de la existencia de algún grado de interacción o comunicación entre humanos. Para ellos, el problema no es la utilización del big data mediante el uso de algoritmos, sino el acuerdo de participar en una conspiración a través de un determinado algoritmo para la fijación de precios.

Ahora bien, en cuanto a prevenir conductas como pricing algorithms, es necesario evaluar si basta con fomentar la consciencia de ilegalidad del actuar de tal manera, o si en cambio es necesario ir más lejos e incluir en la legislación una regla objetiva en el tipo (regla per se). Es decir, incluir una regla prohibitiva, que establezca que por el sólo hecho de programar, contratar o adquirir un algoritmo para la fijación de precios - siempre y cuando este algoritmo cuente con ciertas propiedades y características- se incurra en el ilícito anticompetitivo (Harrington, 2017: 658).

En lo que a pricing algorithms se refiere, la decisión que tienen que tomar las autoridades de defensa de la libre competencia es altamente compleja. En ciertos casos, el intercambio de información puede ser eficiente y, entonces, tendrá un efecto beneficioso para el mercado y también para el bienestar social. Por esta razón, dicho intercambio se convierte en un fin deseado. Pero en muchos mercados, los intercambios de información pueden ser anticompetitivos. Ello nos impone la obligación de ser precavidos para evitar un exceso de regulación, el cual podría impedir que ocurra el intercambio apto para producir los efectos beneficiosos descritos. En palabras de Watson y Zoido (2019: 417):

Es razonable que se examinen estas prácticas con detenimiento, por el potencial riesgo que conllevan. Pero no todos los intercambios de información son iguales. 
Para que un intercambio de información facilite la colusión sin que exista un acuerdo explícito, el mercado en cuestión debe facilitar a las empresas alcanzar términos de coordinación o vigilar la conducta de las empresas (para poder detectar y castigar a aquéllas que se desvían de la coordinación). Y no se debe perder de vista que los intercambios de información son susceptibles de generar eficiencias.

En consecuencia, será muy relevante que la autoridad competente actúe con reflexión y tome esta decisión con prudencia, para analizar los efectos de cada caso y determinar si el intercambio de información realmente lleva a un acuerdo tácito de operación conjunta entre competidores, es decir, que exista la intención de restringir la competencia en el mercado. Puesto que si son intercambios "procompetitivos y no tienen efecto alguno» (Watson y Zoido, 2019: 425), no es recomendable que la autoridad intervenga.

\section{Conclusión}

El propósito de este trabajo fue demostrar cómo el big data puede facilitar ciertas conductas anticompetitivas. Es así razonable concluir que el mundo del big data -es decir, información producida a gran velocidad, de variedad, en volumen, veraz y con valor económico - tiene un gran potencial para introducir mejoras en los bienes y servicios que el mercado ofrece a los consumidores. No obstante, también representa desafíos para el derecho, y en especial para la libre competencia. Por ello, al observar la industria digital e intentar determinar qué conductas son beneficiosas y cuáles son perjudiciales en materia de libre competencia, es importante considerar sus efectos en innovación, en los mercados, en los consumidores y en los trabajadores, toda vez que estos efectos pueden ser positivos desde el punto de vista del bienestar social.

El presente estudio nos permite concluir que el big data puede facilitar conductas anticompetitivas. En primer lugar, puede generar nuevas barreras a la entrada, por ser el big data un activo difícil de replicar. Segundo, el acceso y uso del big data puede producir abusos de poder de mercado tanto en los mercados digitales como en cualquier otra industria.

En lo que a operaciones de concentración se refiere, definir el mercado relevante es uno de los principales desafíos para las autoridades de competencia. Destacan también los riesgos relacionados con las adquisiciones de startups, o aquéllas operaciones en que las partes involucradas se dedican a recolectar o analizar big data, o se encuentran integradas verticalmente en la cadena de valor de este bien económico.

En la misma línea, con el objeto de prevenir la concentración en los mercados, se han propuesto alternativas para atenuar los efectos adversos. Dentro de dichas alternativas se encuentran la de establecer una obligación legal de acceso, invertir la carga de la prueba y modificar los umbrales en fusiones preventivas al menos en determinadas industrias. 
Otra conclusión importante es que por medio del big data, es posible que se produzcan nuevas formas de colusión, ya sea como facilitador, como hub \& spoke o como agente en especial, de los cuales los casos de pricing algorithms son los que representan el mayor desafío desde el punto de vista de la libre competencia.

Por último, la mejor aproximación a la relación entre big data y libre competencia es, por el momento, estar atentos. Puesto que, si la legislación se vuelve insuficiente para regular los efectos del big data, será necesario reconocer la especial naturaleza de este particular mercado y su influencia en otras industrias, para poder profundizar las alternativas adecuadas de regulación.

\section{Referencias}

ACCC, Australian Competition and Consumer Commission (2019). «Digital platforms inquiry: Final report». Disponible en https://bit.ly/3orOdRN.

ACCINeLli, Elvio y Osvaldo Salas (2019). «El estado de bienestar como un bien público no excluible». Estudios Económicos, 34 (2): 243-273. Disponible en https:// bit.ly/3f $21 \mathrm{eFP}$.

BAMBerger, Kenneth A. y Orly Loebel (2017). «Platform market power». Berkeley Tech Law Journal, 32: 1.051-1.092. DOI: 10.15779/Z38NooZT38.

BeNEKe, Francisco y Mark-Oliver Mackenrodt (2018). «Artificial intelligence and collusion». International Review of Intellectual Property and Competition Law, 50: 109-134. DOI: 10.1007/s40319-018-00773-X.

Bravo, Rodrigo, Cristián Briones, Sebastián Faúndez, Gerardo Puelles, Arturo Fuentes, Hernán Bosselin y Ramón Briones (2017). Chile concentrado: Investigación sobre el modelo económico chileno. Santiago: Trayecto Comunicaciones.

BrUCKNER, Matthew A. (2018). «The promise and perils of algorithmic lenders' use of big data». Chicago-Kent Law Review, 93 (1): 3-60. Disponible en https://bit. ly/3omTASq.

BRYAN, Kevin y Erik Hovenkamp (2020). «Startup acquisitions, error costs, and antitrust policy». University of Chicago Law Review, 87 (2): 331-356. Disponible en https://bit.ly/zokjcPO.

Budnik, Gabriel (2019). Libre competencia: Regla per se y colusión. Santiago: Hammurabi.

Bundeskartellamt y Autorité de la Concurrence (2016). «Competition law and data». Disponible en https://bit.ly/3cLTl 5 X.

Cruz, Liliana (2019). «Análisis de concentraciones en economías digitales». En Vanessa Facuse Andreucci y Ana María Montoya Squif (directoras), Desafíos de la libre competencia en Iberoamérica. Santiago: Legal Publishing.

Evans, David S. (2017). «Why the dynamics of competition for online platforms leads to sleepless nights, but not sleepy monopolies». SSRN. DOI: 10.2139/ssrn.3009438. 
EzRACHI, Ariel (2018). «EU competition law goals and the digital economy». Oxford Legal Studies Research, 17. DOI: 10.2139/ssrn.3191766.

Ezrachi, Ariel y Maurice E. Stucke (2016). Virtual competition: The promise and perils of the algorithm-driven economy. Cambridge: Harvard University Press.

-. (2020). «Sustainable and unchallenged algorithmic tacit collusion». Northwestern Journal of Technology and Intellectual Property, 17 (2): 217-26o. Disponible en https://bit.ly/3dJirgZ.

Frigerio, Catalina (2018). «Mecanismos de regulación de datos personales: Una mirada desde el análisis económico del derecho». Revista Chilena de Derecho y Tecnología, 7 (2): 45-80. DOI: 10.5354/0719-2584.2018.50578.

Geradin, Damien y Monika Kuschewsky (2013). "Competition law and personal data: Preliminary thoughts on a complex issue». DOI: 10.2139/ssrn.2216088.

GoldenberG, Juan Luis (2019). «Herramientas del big data y fintech para prevenir y aliviar el sobreendeudamiento del consumidor: Una propuesta». Revista Chilena de Derecho y Tecnología, 8 (2): 5-32. DOI: 10.5354/0719-2584.2019.54051.

HARrington, Joseph H. (2017). «Developing competition law for collusion by autonomous artificial agents». Journal of Competition Law and Economics, 14 (4): 638-671. DOI: 10.1093/joclec/nhzoo1.

Hoffmann-Riem, Wolfgang (2018). Big data: Desafíos también para el derecho. Madrid: Thomson Reuters.

Hu, Han, Yongagan Wen, Tat-Seng Chua y Xuelong Li (2014). «Toward scalable systems for big data analytics: A technology tutorial». IEEE Access, 2: 652-687. DOI: 10.1109/ACCESS.2014.2332453.

KaTZ, Michael y Jonathan Sallet (2018). «Multisided platforms and antitrust enforcement». Yale Law Journal, 127 (7): 2.142-2.175. Disponible en https://bit.ly/37g2tPg.

LASSERre, Bruno y Andreas Mundt (2017). «Competition law and big data: The enforcer's view». Italian Antitrust Review, 4 (1): 87-103. DOI: 10.12870/iar-12607.

LERNER, Andres V. (2014). "The role of 'big data' in online platform competition». DOI: $10.2139 /$ ssrn.2482780.

MACEDo, Luciana (2019). «Economía digital y competencia». En Vanessa Facuse Andreucci y Ana María Montoya Squif (directoras), Desafíos de la libre competencia en Iberoamérica. Santiago: Legal Publishing.

Matos, Margarida (2019). «Los efectos de red potenciados por el big data: Desafíos para la política de competencia». En Vanessa Facuse Andreucci y Ana María Montoya Squif (directoras), Desafíos de la libre competencia en Iberoamérica. Santiago: Legal Publishing.

Navas, Susana (2015). La personalidad virtual del usuario de internet: Tratamiento de la información personal recogida mediante cookies y tecnología análoga. Valencia: Tirant lo Blanch. 
-. (2017). «Datos personales y mercado». En Susana Navas Navarro (directora), Inteligencia artificial: Tecnología derecho. Valencia: Tirant lo Blanch.

OCDE, Organización para la Cooperación y el Desarrollo Económicos (2015). Datadriven innovation: Big data for growth and well-being. París: OECD Publishing. DOI: $10.1787 / 9789264229358$-en.

Rubinfeld, Daniel L. y Michal S. Gal (2017). «Access barriers to big data». Arizona Law Review, 59 (2): 339-382. DOI: 10.2139/ssrn.2830586.

SANZ, Francisco (2018). «Evolución del tratamiento de la colusión en Chile dentro del marco de la defensa de la libre competencia». Ars Boni et Aequi, 14 (2): 11-51. DOI: 10.23854/07192568.2018142Sanz11.

SCHEPP, Nils-Peter y Achim Wambach (2016). «On big data and its relevance for market power assessment». Journal of European Competition Law and Practice, 7 (2): 120-124. DOI: 10.1093/jeclap/lpvo91.

Sims, Rod (2017). «Can robots collude?». Conferencia The ACCC's approach to colluding robots. Disponible en https://bit.ly/3dLrT9Q.

-. (2019). «Data (r)evolution: Consumer welfare and growth in the digital economy». Conferencia Consumer Policy Research. Disponible en https://bit.ly/37b7DvT.

Sokol, D. Daniel y Roisin E. Comerford (2016). «Does antitrust have a role to play in regulating big data?». En Cambridge handbook of antitrust, intellectual property and high tech. Cambridge: Cambridge University Press.

Stigler Center (2019). «Stigler Commitee on digital platforms». Disponible en https://bit.ly/2ASLFli.

STUCKe, Maurice y Allen Grunes (2016). Big data and competition policy. Oxford: Oxford University Press.

Tucker, Darren S. y Hill Wellford (2014). «Big mistakes regarding big data». En Antitrust Source (pp. 1-11). Chicago: American Bar Association.

VALDÉs, Domingo (2006). Libre competencia y monopolio. Santiago: Jurídica de Chile.

VIscusi, W. Kip, Joseph E. Harrington y John M. Vernon (2005). Economics of regulation and antitrust. Cambridge: MIT Press.

Watson, Nadine y Elena Zoido (2019). «Intercambio de información: Análisis económico de efectos». En Vanessa Facuse Andreucci y Ana María Montoya Squif (directoras), Desafíos de la libre competencia en Iberoamérica. Santiago: Legal Publishing.

ZÚÑIGA, Guliana (2019). «Big data y los desafíos que plantea al abuso de posición de dominio». Revista de Actualidad Mercantil, 6: 208-226. Disponible en https://bit. ly/3om $3 x z$ C. 


\section{Sobre la autora}

María Francisca Labbé Figueroa es abogada. Licenciada en Derecho por la Pontificia Universidad Católica de Chile. Magíster Legum en Derecho Internacional, Comercio y Arbitraje por la Universidad de Heidelberg, Alemania, y la Universidad de Chile. Magíster en Dirección y Gestión Tributaria por Universidad Adolfo Ibáñez, Chile. Profesora de Regulación Económica y Profesora Investigadora del Centro de Derecho Regulatorio y Empresa, Facultad de Derecho, Universidad del Desarrollo, Chile. Su correo electrónico es mlabbe@udd.cl. (D) https://orcid. org/0000-0002-1376-0397. 


\title{
REVISTA CHILENA DE DERECHO Y TECNOLOGÍA
}

La Revista de Chilena de Derecho y Tecnología es una publicación académica semestral del Centro de Estudios en Derecho Informático de la Facultad de Derecho de la Universidad de Chile, que tiene por objeto difundir en la comunidad jurídica los elementos necesarios para analizar y comprender los alcances y efectos que el desarrollo tecnológico y cultural han producido en la sociedad, especialmente su impacto en la ciencia jurídica.

\author{
EDITOR GENERAL \\ Daniel Álvarez Valenzuela \\ (dalvarez@derecho.uchile.cl) \\ SITIO WEB \\ rchdt.uchile.cl \\ CORREO ELECTRÓNICO \\ rchdt@derecho.uchile.cl \\ LICENCIA DE ESTE ARTÍCULO \\ Creative Commons Atribución Compartir Igual 4.o Internacional
}

\begin{abstract}
La edición de textos, el diseño editorial
y la conversión a formatos electrónicos de este artículo

estuvieron a cargo de Tipográfica

(www.tipografica.io).
\end{abstract}

